\title{
De Getúlio a Costa e Silva
}

\author{
Newton Bernardes
}

NEWTON BERNARDES é professor titular do Instituto de Fisica da USP.

Palestra proferida durante o simposio em homenagem a Mario Schenberg no IFUSP em 29/11/1990.

\footnotetext{
- Todos os números săo aproximados,
} porém significativos.
Os quinze anos entre a morte de Getúlio (1954) e a morte de Costa e Silva (1969) parecem marcar um período interessante na história da Física no Brasil". Esse perfodo coincide com os quinze anos que marcaram o esforço de Mario Schenberg em prol da Física no Brasil entre o seu retorno da Bélgica (1947-52) e a sua cassação pelo AI-5 (1968). Isso não é por acaso, como também não é por acaso que esse período corresponde ao meu envolvimento direto com a Física do Estado Sólido, a primeira metade (1954-63) no exterior e a segunda no Brasil (1963-69).

Linearmente, sem nenhum julgamento de valor, Getúlio foi letalmente deposto por forças ingentes, assim como letalmente foi deposto Costa e Silva. E esses fatos marcam mudanças radicais na estrutura do ensino e da pesquisa no Brasil.

A morte de Getúlio foi marcada por uma série de escândalos e mexericos (o tal "mar de lama"), como por exemplo naquilo que nos diz respeito, o caso define um desfalque de dois milhões de dólares no CBPF, caso que abalou radicalmente a saúde e o desempenho de Cesar Lattes.

Por volta de 1952 "Física no Brasil" institucionalmente significava física nuclear, de um tipo ou de outro. Veja: 1) no Rio de Janeiro, Lattes se esforçava para a montagem de um sincroton piloto de $8 \mathrm{Mev}$, enquanto que em São Paulo já estava em funcionamento o betatron de Marcelo Damy e logo depois o Van der Graaff de Oscar Sala. Schenberg, recém-chegado do exílio, buscava caminhos e no seu retorno encontrara em São Paulo o recém-chegado americano David Bohm, banido dos EUA pelo macarthismo. Eu acabara de me diplomar aqui na Física da Universidade de São Paulo. Nessa época as forças envolvidas na deposição letal de Getúlio se degladiavam em torno dos conceitos de progresso, nação, etc. A Aeronáutica acabara de instalar em São José dos Campos um complexo tecnológico-educacional CTA-ITA completamente importado dos EUA (com algumas poucas exceções holandesas-alemãs especialistas em aeronaves). Naquele tempo, engenharia no Brasil significava engenharia civil, com leves toques de engenharia mecânica. A implantação da indústria automobilística engatinhava para os primeiros fuscas 1200 . Mas o cerne do desenvolvimento estava sendo focalizado na indústria eletrônica. Muitas indústrias multinacionais se instalavam na via Dutra, entre Jacaré e São José dos Campos, nas proximidades do CTA, como por exemplo a Philips, voltada para a eletrônica. Até Oscar Sala, sem querer, viu seus estagiários no Van der Graaf se tornarem desejáveis na novidade vácuo-industrial.

$\mathrm{Na}$ época, as vistas estavam voltadas para os dispositivos eletrônicos, impulsionados pela recente descoberta por Bardeen, Brittain e Schokley (BBS) do transistor de estado sólido e pelas perspectivas de desenvolvimento dos primeiros computadores eletrônicos, mesmo que a válvulas. No ITA os alunos mais brilhantes cobiçavam e eram cobiçados pelo curso de Engenharia Eletrônica, em detrimento das alternativas de Aeronaves e Aerovias. Tudo isso para salientar o papel que o complexo de ação militar-industrial começou a desempenhar na história da Física no Brasil.

Na Época, Schenberg tinha 38 anos, Bohm 37 e eu 21. Apesar de ambos comunistas, cada um a seu jeito, Schenberg e Bohm não se afinavam tanto. Não obstante, ambos auscultavam os murmúrios de novos rumos na Física (por exemplo, BBS, prêmio Nobel 1957 pelo transistor de 1950). Bohm, com alguma vivência fora da Física Nuclear (Bohm \& Pines, 1950, no plasma de elêtrons em metais), me recomendara estudar Física do Estado Sólido com Seitz em Illinois, como algo de futuro. Assim, recém-formado, passei quase dois anos no ITA em São Jose dos Campos, no Departamento de Física, me preparando para viajar enquanto aguardava a bolsa de estudos. Ao tempo da morte de Getúlio fui para Illinois. Naquela época, minhas relações com Schenberg eram apenas incidentais: nem aluno nem colega.

Schenberg em São Paulo continuava sua busca de rumos para a Física em São Paulo. $\mathrm{Na}$ época já desenvolvera interesse pela Mecânica Estatística, tendo publicado trabalhos de valor em Il Nuovo Cimento na área de Mecânica Estatística. Seu interesse pela Me- 
cânica Estatística continuou até a década de 80, tendo nessa década ministrado famosos cursos sobre $o$ assunto.

No entanto o que aqui quero chamar a atenção é que na primeira metade do período aqui analisado (da qual só tenho notícias, já que me encontrava nos EUA), Schenberg, se posicionando na vanguarda a favor do "Estado Solido" e dos "computadores", se viu em oposição às máquinas de Sala e Damy, incluindo o "reator nuclear". Época de Jânio governador e Juscelino presidente. Algumas vezes seu posicionamento tático se tornou dificilmente defensável.

Por volta de 1960, Schenberg, decidido a implantar a Física do Estado Sólido na USP, me consultou nos EUA sobre os rumos a tomar. Eu, apesar de teórico, aconselheio a implantar um Laboratório de Baixas Temperaturas de nível internacional. Ao mesmo tempo Schenberg se empenhava em trazer Lattes de volta do Rio de Janeiro, onde o sincroton não vingara. Na época predominava a famosa "verba federal", que constitúa quass toda a estrutura financeira do Departamento de Física, que tinha que ser votada anualmente no Congresso. A repartição dessa verba entre os vários grupos do Departamento era o maior "cavalo de batalha" na qual Schenberg sempre defendeu os grupos emergentes principalmente para a implantação do Laboratório de Baixas Temperaturas do qual Schenberg foi pioneiro e paladino, da mesma forma que para os grupos de "emulsões" e do "computador". Embora extemporâneo quero salientar, por um lado, o papel decisivo do deputado federal Lauro Cruz (pai da nossa Marilia Cruz) na outra ponta (Brasflia) da "verba federal", e por outro, a vinda para o Departamento de Física, de Luiz Queiroz Orsini, professor na Politécnica, para implantar os primeiros grupos e cursos de Eletrônica no Departamento de Física, decorrência principalmente das necessidades operacionais de Oscar Sala.

Então, a convite de Mario Schenberg, por volta de 1961-62, eu vim a São Paulo com John Daunt e af foram lançados os primeiros passos para a implantação de um grupo de Baixas Temperaturas, fundamentalmente um liquefator de Nitrogênio e um liquefator de Hélio, e posteriormente um refrigerador de He3. Logo em seguida, sempre sob o patroćnio de Mario Schenberg, vieram as equipes comercio-industriais da firma Arthur Little, e Mario Schenberg cuidou tanto de aspecto de construção de ediff́cios como da arregimentação de jovens interessados em participar desse empreendimento. Alguns se dispersaram, mas muitos permaneceram no atual Departamento de Materiais e Mecânica. Assim, em 1963, pela primeira vez no Brasil, o He foi liquefeito e manipulações em torno de 2 Kelvin se tornaram rotina no nosso Laboratório de Baixas Temperaturas. Logo depois, com o refrigerador de $\mathrm{He} 3$, temperaturas de décimos de grau Kelvin se tornaram operacionais. Dessa forma, a partir de 1964, o grupo de Estado Sólido pôde se estruturar em torno de problemas de pesquisa e não em torno de montagem de equipamento. $\mathrm{O}$ grupo se ampliou, tanto em termos de pessoas nacionais como de especialistas estrangeiros. $\mathrm{O}$ apoio de Mario Schenberg foi capital para todo esse empreendimento.

Logo em 64 Mario Schenberg foi preso pelos militares e impedido de qualquer atividade acadêmica organizada. Eu, mal-e-mal, continuei a sua tarefa de dirigir o Laboratório de Baixas Temperaturas e Estado Sólido, e sem dúvida todos sentiram a falta da presença de Mario Schenberg. Em 1965 Mario Schenberg já havia sido liberado da prisão e retomou suas atividades no Departamento de Física. Na época se empenhava em iniciar um grupo de História da Ciência e, enfrentando as maiores dificuldades formais, trouxe para São Paulo Plinio Sussekind Rocha, recém-cassado na Faculdade Nacional de Filosofia no Rio de Janeiro, que durante pouco tempo (infelizmente devido ao seu prematuro falecimento) desenvolveu no nosso Departamento de Física da FFCL as primeiras atividades regulares em História da Ciência, ministrando cursos e orientando jovens estudantes. Nessa época o grupo de emulsões de Cesar Lattes, também sob o patrocínio de Mario Schenberg, já se achava em funcionamento no nosso departamento.

Em 1967 eu convencera Mario Schenberg da oportunidade de se implantar em São Paulo um grupo de pesquisa em lasers. Foram contatados Sergio Porto e Rogério Cerqueira Leite que já por alguns anos, nos laboratórios da Bell, estavam envolvidos em pesquisas na física de lasers. Ambos, por via indireta, provenientes do ITA, Sergio como professor e Rogério como aluno. Internamente, Mario Schenberg abriu nova frente de luta para a implantação desse grupo de lasers, tanto no que se refere às instalações quanto à contratação do pessoal envolvido. Vale a pena lembrar que, à primeira vista, Mario Schenberg e Rogério Cerqueira Leite politicamente estavam situados em extremos opostos. Curioso, porem, notar que, apesar disso, durante sua viagem de 1968 aos EUA Mario Schenberg, antes sem nenhum relacionamento pessoal com Rogério, foi vi- 
sitá-lo em New Jersey e lá permaneceu hospedado na residência de Rogério por dois meses ou mais. E eu sou testemunha da relação mútua de respeito e admiração que a partir daí se desenvolveu entre eles. Por uma série de motıvos, que não é oportuno nem enumerar, esse enpreendimento "laser" não deu certo em São Paulo e Rogério Cerqueira Leite foi com o seu grupo para Campinas num empreendimento em escala muito maior com Sergio Porto e Ripper.

Por volta de 1968 chegamos ao fim do período que estou aqui analisando. Novas forças políticas, fenômeno diverso, porém bastante semelhante ao de 1954, impulsionaram a nação e a universidade para novos buracos. O general Costa e Silva foi letalmente deposto. Veio o AI-5. A Reforma Universitária foi duramente implantada. As faculdades, entre elas a nossa de Filosofia, Ciências e Letras, foram dissolvidas. As cátedras foram extintas. Surgiram os institutos com seus departamentos. Os catedráticos foram relocados. Muitos compulsoriamente aposentados, e até proibidos de freqüentar a universidade. Entre eles Mario Schenberg.

Com tudo isso eu quis salientar:

1) a ruptura que se deu no começo dos anos 50; ruptura tecnológico-científica na qual a física brasileira lança, de vários modos, seus primeiros passos para uma Física não-nuclear. Ruptura essa para atender os interesses da nova ordem tecnológico-industrial que no plano institucional incluíra a criação do ITA, e que no plano político inclurra a anistia política de gente como Mario Schenberg, mas que inclúra também a morte de Getúlio;

2) uma nova ruptura em 1969 na qual a universidade é organizada de modo a diluir o poder, principalmente pela dissolução das cátedras, pela criação dos institutos e sua subdivisão em departamentos. Típica conseqüência dessa nova ruptura foi a mudança de rumos imprimida à recém-criada Unicamp, que agora passou a concentrar suas vistas na direção dos "dispositivos". Tudo muito parecido com 1954, que incluíra a criação do ITA sob moldes americanos;

3) movido pela ocasião, eu também quis salientar os papéis que Mario Schenberg desempenhou no período entre essas duas rupturas que, ironicamente, se inicia com a sua anistia e termina com a sua cassação e aposentadoria compulsória.

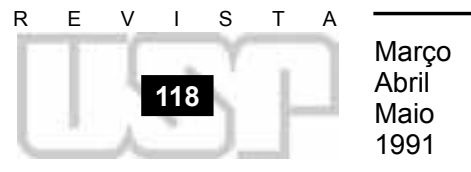

